\title{
JIMMBA
}

Jurnal Ilmiah Mahasiswa Manajemen, Bisnis dan Akuntansi

Homepage: $h$ ttp://journal.stieputrabangsa.ac.id/index.php/jimmba/index

\section{Pengaruh Self Image Congruence, Luxury Value Dan Product Attribute Terhadap Repurchase Intention Melalui Satisfaction Sebagai Variabel Intervening (Studi Pada Pengguna Smartphone Vivo Keluaran Tahun 2018-2019 Di Kabupaten Kebumen)}

\author{
Lusiana Safitri', Sulis Riptiono ${ }^{2}$ \\ ${ }^{1}$ Sekolah Tinggi Ilmu Ekonomi Putra Bangsa \\ 2Sekolah Tnggi Ilmu Ekonomi Putra Bangsa \\ Email: lusiana02011999@gmail.com
}

\section{ARTICLE INFO}

Article History:

Received: June $10^{\text {th }} 2020$

Accepted: August 19th 2020

Published: August 31st 2020

Keywords:

Self Image Congruence, Luxury Value, Product Attribute, Satisfaction, dan Repurchase Intention.

\begin{abstract}
Penelitian ini bertujuan untuk menganalisis pengaruh self image congruence, luxury value, dan product attribute terhadap repurchase intention melalui satisfaction sebagai variabel intervening pada pengguna smartphone Vivo keluaran tahun 2018-2019 di Kabupaten Kebumen. Target populasi pada penelitian ini adalah masyarakat di Kabupaten Kebumen yang menggunakan smartphone Vivo keluaran tahun 2018-2019 dengan jumlah sampel 100 responden. Penelitian ini menggunakan metode analisis deskriptif dan statsistika dengan metode nonprobability sampling dan jenis tekniknya yaitu purposive sampling. Berdasarkan metode statistika dilakukan uji validitas, uji reliabilitas, uji asumsi klasik (uji multikolinieritas, uji heterokedastisitas, dan uji normalitas), uji t, uji koefisien determinasi, analisis jalur, dan uji sobel. Hasil penelitian ini menunjukkan bahwa berdasarkan uji validitas dan uji reliabilitas semua variabel dinyatakan valid dan reliabel. Berdasarkan uji t sub stuktur I variabel self image congruence berpengaruh positif dan signifikan terhadap satisfaction, luxury value berpengaruh positif dan signifikan terhadap satisfaction, product attribute berpengaruh positif dan siginifikan. Kemudian untuk sub struktur II variabel self image congruence berpengaruh positif dan siginifikan terhadap repurchase intention, product attribute tidak berpengaruh positif dan tidak signifikan terhadap repurchase intention, satisfaction berpengaruh positif dan signifikan terhadap repurchase intention. Serta satisfaction dapat memediasi antara self image congruence dan product attribute terhadap repurchase intention.
\end{abstract}

\section{Pendahuluan}

Perkembangan teknologi pada saat ini sangatlah pesat dibandingkan dengan sebelumnya. Tidak terkecuali pada perkembangan smartphone dengan sistem operasi android yang saat ini sangat unggul. Smartphone adalah telepon genggam atau telepon seluler pintar yang dilengkapi dengan fitur mutakhir serta memiliki kemampuan pemrosesan tinggi yang sangat 
memudahkan penggunanya. Oleh karena itu, dampaknya adalah aktifitas masyarakat tidak bisa lepas dari penggunaan smartphone.

Pasar Indonesia saat ini dijadikan sebagai target penjualan smartphone yang sangat bagus. Hal tersebut dibuktikan dengan banyaknya pengguanaan smartphone di Indonesia yang merupakan urutan ke enam dan sebelumnya ada China, India, Amerika Serikat, Brazil, dan Rusia (idntimes.com). Kini diperkirakan penduduk Indonesia sebanyak 261 juta jiwa telah menggunakan smartphone sebanyak 236 juta unit. Jumlah pengguna akan semakin bertambah karena tidak adanya batasan usia ataupun jumlah kepemilikan dan penggunaan smartphone di Indonesia.

Perubahan perilaku masyarakat tidak hanya memanfaatkan kecanggihan smartphone sebagai alat untuk mengirimkan pesan singkat (SMS) ataupun alat untuk menelfon saja, namun mereka lebih cenderung menggunakan smartphone sebagai alat untuk mengambil foto di setiap aktivitas. Karena life style masyarakatnya yang sangat exaited terhadap perkembangan smartphone yang terus menerus berkembang. Oleh karena itu, para produsen smartphone sangat gencar untuk meluncurkan produk-produk smartphone mereka secara berkala yang tentunya selalu menghadirkan inovasi-inovasi terbaru khususnya pada kamera supaya dapat memenuhi kebutuhan konsumen.

Banyaknya masyarakat Indonesia yang sangat menyukai foto menggunakan smartphone, membuat produsen memanfaatkan peluang ini dengan mengeluarkan smartphone yang memiliki kualitas kamera sesuai dengan harapan konsumen. Harapan yang diinginkan konsumen adalah memiliki smartphone dengan kualitas kamera beresolusi tinggi untuk menunjang hobby maupun aktifitas mereka. Salah satu smartphone yang memiliki inovasi kamera cukup memiliki resolusi tinggi adalah Vivo keluaran tahun 2018-2019.

Kabupaten Kebumen sendiri banyak pengguna smartphone Vivo keluaran tahun 2018-2019 yang mampu menunjang kebutuhan, memiliki desain dan model yang mewah sehingga mampu meningkatkan citra diri si pengguna. Selain pengguna yang cukup banyak, kondisi penjualan di Kebumen juga meningkat. Hal tersebut dibuktikan dengan bertambah banyaknya counter smartphone Vivo khususnya di Kabupaten Kebumen.

Vivo adalah perusahaan elektronik yang berasal dari Dong Guan, provinsi Guang Dong, Tiongkok. Perusahaan ini didirikan pada tahun 2009 dan memulai debutnya di Indonesia pada tahun 2014. Smartphone Vivo di produksi di negara China, di impor dari Hongkong ke Indonesia, India, Malaysia dan Vietnam. Vivo adalah smartphone yang berbasis konsumen dan terus mengembangkan inovasi teknologi yang mendukung gaya hidup mereka.

\section{Kajian Teori dan Telaah Literatur}

\section{Product Attribute}

Product attribute merupakan segala hal yang melekat pada produk atau menjadi bagian dari produk itu sendiri (Nugroho dkk, 2015). Atribut produk memegang peran yang sangat vital, karena atribut produk merupakan salah satu faktor yang dijadikan bahan pertimbangan oleh konsumen ketika akan memebeli produk produk tersebut. Atribut produk adalah unsurunsur yang dipandang penting oleh konsumen dan dijadikan dasar pengambilan keputusan (Tjiptono, 2001). Atribut produk adalah suatu komponen yang merupakan sifat-sifat produk yang menjamin agar produk tersebut dapat memenuhi kebutuhan dan keinginan yang diterapkan oleh pembeli. Ada beberapa atribut yang melengkapi dan menyertai dalam pengembangan suatu produk atau jasa yang melibatkan pendefinisian manfaat yang akan 
ditawarkan produk atau jasa. Manfaat ini dikomunikasikan dan dihantarkan oleh atribut produk seperti kualitas produk, fitur, serta gaya dan desain. Atribut produk adalah mutu, sifat dan rancangan yang terdapat dalam suatu produk dan mempengaruhi keputusan pembelian dalam pembelian suatu produk (Kotler \& Amstrong, 2004:283). Menurut Goh et al (2016), atribut produk memiliki indikator sebagai berikut: (a) produk bervariasi, (b) pengalaman layanan pelanggan, $(\mathrm{c})$ produk selalu berinovasi, $(\mathrm{d})$ produk berkualitas memiliki fitur canggih dan desain produk menarik.

\section{Luxury Value}

Terdapat tiga segmen dalam luxury value, yang pertama yaitu menekankan pada nilai fungsional dari produk yang diinginkan untuk dibeli. Pada perspektif ini, menandakan kualitas barang dan layanan yang sebenarnya seperti yang dirasakan oleh konsumen. Jenis konsumen dengan klasifikasi ini sangat mementingkan kualitas produk. Mereka melihat dari perspektif seberapa baik kinerja produk dan efisiensi utamanya (Goh et al, 2016). Dalam konteks perilaku konsumen, kualitas yang dirasakan menjadi elemen penting dalam klasifikasi barang dan jasa. Nilai fungsional memiliki kemampuan untuk meningkatkan niat pembelian ulang. Kemudian yang kedua signifikasi empiris yang melibatkan persepsi konsumen terhadap merek mewah karena orang sering merasa barang-barang mewah memilki nilai keunikan dan harganya. Selain itu, hal ini juga menunjukkan faktor yang langka dalam persepsi setiap orang. Yang ketiga adalah berfokus pada nilai mewah sebagai simbolik, yang melambangkan kekayaan, prestise, status dan kemahalan produk tersebut. Indikator luxury value menurut Goh et al (2016) yaitu: (a) status atau reputasi produk, (b) keunikan produk, (c) keekslusifan produk, (d) produk berkarakter.

\section{Self Image Congruence}

Citra merupakan salah satu dasar yang digunakan konsumen untuk menentukan seberapa cocok kepribadian mereka dengan citra ritel tertentu (Lindquise dan Sirgy, 2009). Citra diri yang khas dimiliki oleh setiap individu, citra diri yang khas tersebut merupakan hasil dari perkembangan latar belakang dan pengalaman individu tersebut (Widjiono dan Japarianto, 2015). Self image congruence menunjukkan tingkat dimana konsumen memandang diri mereka sebagai individu yang sesuai dengan tujuan produk tersebut diproduksi (Hanggara dan Brahmana, 2015). Menurut Tammubua (2017) terdapat empat indikator self image congruence, yaitu: (a) actual Self Congruity, Ideal Self Congruity, Social Self Congruity, Ideal Social Self Congruity

\section{Satisfaction}

Satisfaction merupakan kunci dalam menciptakan loyalitas pelanggan (Espejel et al, 2008). Menurut Kotler dan Keller (2009), satisfaction adalah perasaan senang atau kecewa yang timbul dari persepsi terhadap kinerja actual produk. Loyalitas pelanggan akan timbul saat konsumen merasa puas akan produk yang akan dikonsumsinya (Jayaputra, 2009). Satisfaction adalah perasaan senang atau kecewa seseorang yang muncul setelah membandingkan persepsi atau kesan dengan kinerja suatu produk dan harapan-harapannya (Kotler, 2005). Satisfaction di tentukan oleh persepsi pelanggan atas performance produk atau jasa dalam memenuhi harapan pelanggan. Pelanggan merasa puas apabila harapannya terpenuhi atau akan sangat puas jika harapan pelanggan terlampaui (Irawan, 2008). Menurut Goh et al (2016) bahwa indikator kepuasan ada empat yaitu: (a) puas terhadap kinerja produk, (b) puas terhadap desain produk, (c) puas terhadap nilai produk, (d) puas terhadap ekslusivitas produk. 


\section{Repurchase Intention}

Intention digambarkan sebagai suatu situasi seseorang sebelum melakukan suatu tindakan yang dapat dijadikan dasar untuk memprediksi perilaku atau tindakan tersebut. Kotler dan Keller (2009) menyatakan bahwa niat merupakan suatu keadaan dalam diri seseorang, pada dimensi subyektif yang meliputi hubungan antar orang itu sendiri dengan beberapa tindakan. Niat konsumen mengacu pada hasil dari tindakan yang kelihatan dalam situasi, yaitu niat untuk melakukan tindakan respon nyata khusus untuk diramalkan. Kotler dan Keller (2008) berpendapat bahwa "setelah konsumen membeli produk tersebut, konsumen bisa puas atau tidak puas dan terlibat dalam perilaku pasca pembelian. Pembelian yang puas akan kembali membeli produk, memuji produk yang dibelinya dihadapan orang lain, sedikit menarik perhatian pada merek dan iklan pesaing dan membeli produk lain dari perusahaan yang sama". Menurut Engel et al, (2001) menyatakan "a specific type of purchase intention is repurchase intention, which reflect whether we anticipate buying the same product or brand again". Dari pengertian di atas dijelaskan bentuk spesifik dari niat pembelian adalah niat pembelian ulang, yang mencerminkan harapan untuk membeli ulang produk atau merek yang sama. Menurut Nikbin et al (2011) dimensi repurchase intentions yang digunakan dapat diukur dengan tiga indikator sebagai berikut: (a) menggunakan kembali, (b) pilihan utama untuk pembelian selanjutnya, (c) ada niat yang kuat untuk mencoba jenis produk yang lain.

\section{Model empiris}

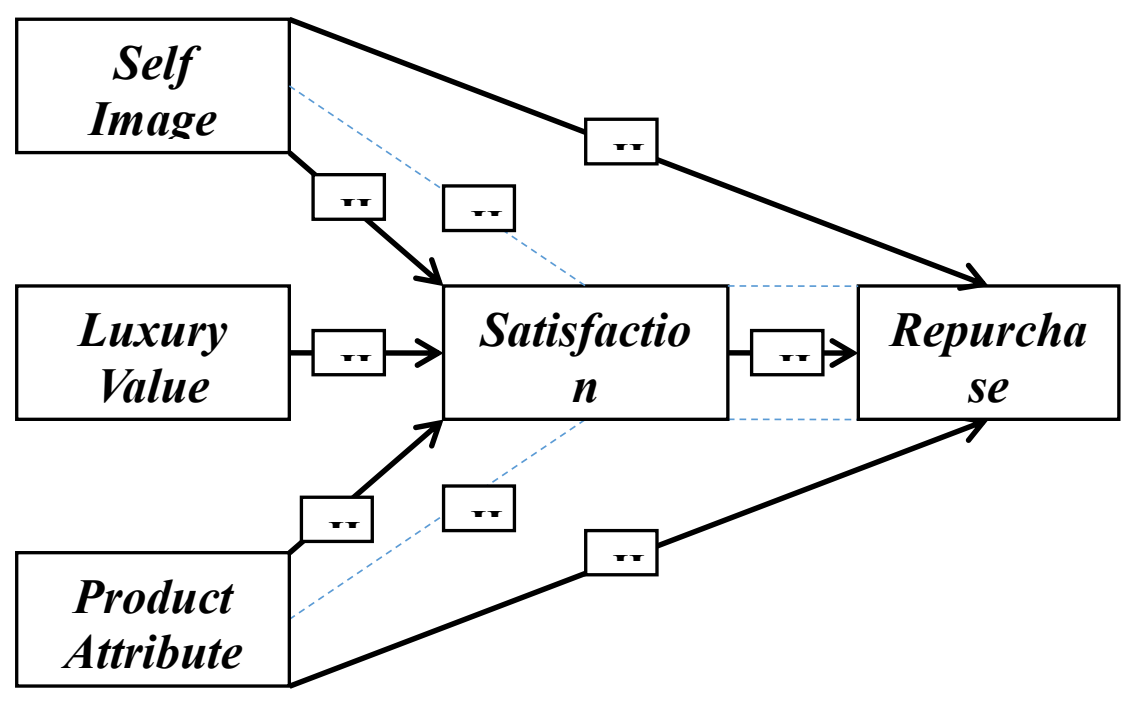

Gambar 1. Model Penelitian

\section{Metode Penelitian}

Populasi dalam penelitian ini adalah semua konsumen yang menggunakan smartphone Vivo keluaran tahun 2018-2019 di Kabupaten Kebumen. Jumlah sampel yang digunakan dalam penelitian ini sebanyak 100 responden. Teknik sampel yang digunakan dalam penelitian ini adalah metode nonprobability sampling, dimana teknik pengambian sampel yang tidak memberikan peluang atau kesempatan sama bagi setiap unsur atau anggota populasi untuk dipilih menjadi sampel. Dalam nonprobability sampling akan digunakan teknik purposive sampling yaitu teknik untuk menentukan sampel penelitian dengan beberapa pertimbangan 
tertentu yang bertujuan agar data yang diperoleh nantinya bisa lebih representatif (Sugiyono, 2010). Sampel dalam penelitian ini yaitu masyarakat di Kecamatan Kebumen yang menggunakan smartphone Vivo keluaran tahun 2018-2019 di Kabupaten Kebumen. Pada penelitian ini menggunakan skala likert 5 poin dan teknik analisisdata yang digunakan adalah analisis kuantitatif menggunakan program SPSS 21 for windows.

\section{Hasil dan Pembahasan}

\section{Pengujian validitas dan reliabilitas}

Tabel 1. Hasil Pengujian Validitas dan Reliabilitas

\begin{tabular}{|c|c|c|c|c|c|c|}
\hline Variabel & $\begin{array}{c}\text { Item } \\
\text { Pertanyaan }\end{array}$ & $\begin{array}{c}\mathrm{R} \\
\text { hitung }\end{array}$ & $\begin{array}{c}\mathrm{r} \text { tabel } \\
(\mathrm{df}= \\
\mathrm{n}-\mathrm{k})\end{array}$ & $\begin{array}{l}\text { Cronbach } \\
\text { Alpha (a) }\end{array}$ & $\begin{array}{c}\mathrm{r} \\
\text { kritis }\end{array}$ & Signifikansi \\
\hline Self Image & SIC 1 & 0,724 & 0,1966 & 0,730 & 0,60 & 0,000 \\
\hline \multirow{3}{*}{$\begin{array}{c}\text { Congruence } \\
\text { (X1) }\end{array}$} & SIC 2 & 0,758 & 0,1966 & & & \\
\hline & SIC 3 & 0,799 & 0,1966 & & & \\
\hline & SIC 4 & 0,711 & 0,1966 & & & \\
\hline \multirow{4}{*}{$\begin{array}{l}\text { Luxury Value } \\
\text { (X2) }\end{array}$} & LV 1 & 0,733 & 0,1966 & 0,844 & 0,60 & 0,000 \\
\hline & LV 2 & 0,859 & 0,1966 & & & \\
\hline & LV 3 & 0,838 & 0,1966 & & & \\
\hline & $\mathrm{LV} 4$ & 0,873 & 0,1966 & & & \\
\hline \multirow{4}{*}{$\begin{array}{l}\text { Product } \\
\text { Attribute } \\
\text { (X3) }\end{array}$} & PA 1 & 0,675 & 0,1966 & 0,726 & 0,60 & 0,000 \\
\hline & PA 2 & 0,779 & 0,1966 & & & \\
\hline & PA 3 & 0,727 & 0,1966 & & & \\
\hline & PA 4 & 0,779 & 0,1966 & & & \\
\hline \multirow{4}{*}{$\begin{array}{l}\text { Satisfaction } \\
(\mathrm{Y} 1)\end{array}$} & S 1 & 0,765 & 0,1966 & 0,850 & 0,60 & 0,000 \\
\hline & S 2 & 0,872 & 0,1966 & & & \\
\hline & S 3 & 0,848 & 0,1966 & & & \\
\hline & S 4 & 0,849 & 0,1966 & & & \\
\hline \multirow{3}{*}{$\begin{array}{l}\text { Repurchase } \\
\text { Intention } \\
(\mathrm{Y} 2)\end{array}$} & RI 1 & 0,935 & 0,1966 & 0,932 & 0,60 & 0,000 \\
\hline & RI 2 & 0,952 & 0,1966 & & & \\
\hline & RI 3 & 0,928 & 0,1966 & & & \\
\hline
\end{tabular}

Sumber: Data primer yang sudah diolah (2020).

Berdasarkan tabel 1 semua variabel mempunyai $r$ hitung lebih besar dari $r$ tabel, sehingga semua butir pertanyaan kuesioner dalam penelitian ini dinyatakan valid, yang artinya butirbutir pertanyaan dapat digunakan untuk mengukur apa yang seharusnya diukur. Tabel di atas juga menunjukkan bahwa variabel independen maupun variabel dependen memiliki nilai Cronbach Alpha lebih besar dari r kritis yaitu 0,60 sehingga dapat disimpulkan bahwa semua instrumen dalam penelitian ini dinyatakan reliabel. 


\section{Uji hipotesis}

\section{Uji parsial (uji $t)$}

Tabel 2. hasil uji $t$ substruktural 1 dan 2

\begin{tabular}{|c|c|c|c|c|c|}
\hline \multirow[b]{2}{*}{ Model } & \multicolumn{2}{|c|}{$\begin{array}{l}\text { Unstandardized } \\
\text { Coefficients }\end{array}$} & \multirow{2}{*}{$\begin{array}{l}\text { Stand } \\
\text { ardize } \\
\text { d } \\
\text { Coeffi } \\
\text { cients } \\
\text { Beta }\end{array}$} & \multirow[b]{2}{*}{ t } & \multirow[b]{2}{*}{ Sig. } \\
\hline & B & $\begin{array}{l}\text { Std. } \\
\text { Enror }\end{array}$ & & & \\
\hline 1. (Constant & 0,871 & 1,067 & & 0,816 & 0,416 \\
\hline $\begin{array}{c}\text { Self Image } \\
\text { Congruenc } \\
e\end{array}$ & 0,166 & 0,060 & 0,220 & 2,751 & 0,007 \\
\hline $\begin{array}{c}\text { Luxury } \\
\text { Value }\end{array}$ & 0,202 & 0,091 & 0,224 & 2,224 & 0,028 \\
\hline $\begin{array}{l}\text { Product } \\
\text { Attribute }\end{array}$ & 0,554 & 0,111 & 0,452 & 4,972 & 0,000 \\
\hline
\end{tabular}

Sumber: Data primer diolah, 2020.

\begin{tabular}{|c|c|c|c|c|c|}
\hline \multirow[t]{2}{*}{ Model } & \multicolumn{2}{|c|}{$\begin{array}{c}\text { Unstandardized } \\
\text { Coefficients }\end{array}$} & \multirow{2}{*}{$\begin{array}{l}\text { Stand } \\
\text { ardize } \\
\text { d } \\
\text { Coeffi } \\
\text { cients } \\
\text { Beta }\end{array}$} & \multirow[b]{2}{*}{$\mathrm{T}$} & \multirow[b]{2}{*}{ Sig. } \\
\hline & B & $\begin{array}{l}\text { Std. } \\
\text { Error }\end{array}$ & & & \\
\hline $\begin{array}{c}\text { 1.(Constant } \\
\text { ) }\end{array}$ & $-1,387$ & 1,251 & & $-1,108$ & 0,271 \\
\hline $\begin{array}{c}\text { Self Image } \\
\text { Congruenc } \\
e\end{array}$ & 0,217 & 0,069 & 0,272 & 3,153 & 0,002 \\
\hline $\begin{array}{l}\text { Product } \\
\text { Attribute }\end{array}$ & 0,133 & 0,132 & 0,103 & 1,009 & 0,316 \\
\hline Satisfaction & 0,450 & 0,116 & 0,425 & 3,861 & 0,000 \\
\hline
\end{tabular}

Sumber: Data primer diolah, 2020.

\section{Pembahasan}

Hasil penelitian menunjukkan bahwa terdapat pengaruh positif dan signifikan self image congruence terhadap satisfaction. bahwa kosumen yang menggunakan Vivo keluaran tahun 2018-2019 memiliki kesesuaian citra diri mereka dengan smartphone Vivo keluaran tahun 20182019. Semakin tinggi citra smartphone Vivo keluaran tahun 2018-2019 dengan citra diri konsumen makan semakin tinggi juga kepercaaan konsumen terhadap smartphone Vivo keluaran tahun 2018-2019.

Hasil penelitian menunjukkan bahwa luxury value berpengaruh positif dan signifikan terhadap satisfaction. Apabila smartphone Vivo keluaran tahun 2018-2019 memiliki nilai mewah seperti yang ada pada casingnya, maka akan meningkatkan kepuasan. Semakin tinggi nilai mewah yang ada pada smartphone Vivo keluaran tahun 2018-2019 maka akan semakin tinggi juga kepercayaan konsumen terhadap smartphone Vivo keluaran tahun 2018-2019.

Hasil penelitian menunjukkan bahwa product attribute berpengaruh positif dan signifikan terhadap satisfaction, smartphone Vivo keluaran tahun 2018- 2019 memiliki atribut yang baik dan meningkatkan kepuasan. Semakin banyak atribut yang ada pada smartphone Vivo keluaran tahun 2018-2019 maka akan semakin tinggi juga kepercayaan konsumen. Karena keinginan dan kebutuhan konsumen dapat terpenuhi.

Hasil penelitian menunjukkan self image congruence berpengaruh positif dan signifikan terhadap repurchase intention. Kosumen smartphone Vivo keluaran tahun 2018-2019 memiliki kesesuaian citra diri mereka dengan smartphone Vivo karena mampu meningkatkan niat beli ulang. Semakin tinggi kesesuaian citra produk maka akan semakin tinggi niat pembelian ulang konsumen terhadap smartphone Vivo keluaran tahun 2018-2019.

Hasil penelitian menunjukkan bahwa product attribute tidak berpengaruh terhadap repurchase intention. Atribut smartphone Vivo keluaran tahun 2018 sampai 2019 tidak dapat meningkatkan niat beli ulang konsumen. 
Hasil penelitian menunjukkan bahwa satisfaction berpengaruh positif dan signifikan terhadap variabel repurchase intention. Kosumen smartphone Vivo keluaran tahun 2018 sampai 2019 memiliki kepuasan dari model produknya dan fitur-fiturnya. Sehingga mampu meningkatkan niat beli ulang.

Hasil penelitian menunjukkan bahwa terdapat pengaruh positif dan signifikan self image congruence terhadap repurchase intention melalui satisfaction. Satisfaction dapat memediasi self image congruence dengan repurchase intention karena smartphone Vivo keluaran tahun 2018-2019 memiki citra produk yang sesuai dengan citra konsumen. Sehingga konsumen memiliki niat beli ulang smartphone Vivo.

Hasil penelitian menunjukkan bahwa terdapat pengaruh positif dan signifikan product attribute terhadap repurchase intention melalui satisfaction. Satisfaction dapat memediasi product attribute dengan repurchase intention karena smartphone Vivo keluaran tahun 2018-2019 memiki atribut produk yang dapat memenuhi kebutuhan dan keinginan konsumen. Misalnya pada kualitas kamera yang dimiliki smartphone Vivo keluaran tahun 2018-2019 di Kabupaten Kebumen.

\section{Penutup dan Saran}

Self Image Congruence menunjukkan tingkat dimana konsumen memandang diri mereka sebagai individu yang sesuai dengan tujuan produk tersebut diproduksi. Banyak dari kalangan konsumen akan mempertimbangkan suatu produk yang mereka beli dengan citra dirinya. Maka dari itu, PT. Vivo Indonesia perlu melakukan riset yang lebih mendalam terhadap produk yang mereka pasarkan supaya produk tersebut dapat sesuai dengan citra diri para konsumen.

Luxury value merupakan nilai mewah yang melekat pada suatu produk yang menandakan pemberian pandangan penampilan standar hidup yang tinggi dan status konsumen ke dalam status sosial yang dipilih. Pada umumnya luxury value banyak dipertimbangkan oleh konsumen kelas menengah ke atas. Maka dari itu, PT. Vivo Indonesia baiknya meningkatkan nilai mewah pada smartphone yang diproduksi. Supaya penjualan smartphone Vivo terus meningkat dan lebih diminati oleh konsumen kelas menengah ke atas.

Product attribute merupakan segala hal yang melekat pada produk atau menjadi bagian dari produk itu sendiri. Smartphone Vivo keluaran tahun 2018-2019 memiliki atribut yang mendukung kebutuhan para konsumen secara baik seperti fitur kamera yang bagus. Maka dari itu, PT. Vivo Indonesia diharapkan dapat meningkatkan kualitas dan fitur-fitur yang semakin baik. Sehingga smartphone Vivo semakin digemari oleh konsumen.

Satisfaction merupakan kunci dalam menciptakan loyalitas pelanggan yang ditandai dengan perasaan senang atau kecewa dari konsumen terhadap produk yang mereka gunakan. Apabila keinginan dan kebutuhan konsumen terpenuhi dari produk yang mereka gunakan maka konsumen akan merasa senang sehingga mereka akan puas. Maka penting bagi perusahaan Vivo Indonesia untuk meningkatkan hal-hal yang mampu memberikan kepuasan bagi konumen. Sehingga konsumen loyal dan akan melakukan pembelian terus-menerus.

Repurchase Intention merupakan niat yang ada pada benak konsumen untuk melakukan pembelian ulang produk yang mereka gunakan sebelumnya. Hal tersebut sebelumnya dikarenakan oleh faktor kepuasan yang dirasakan oleh konsumen sehingga konsumen memiliki niat pembelian ulang terhadap produk yang sama. 


\section{Referensi}

Engel, J.F., G.Blackwell, dan P.W.Miniard. 2001. Perilaku Konsumen. Jilid 1 Binarupa Aksara, Jakarta.

Espejel, Joel, Cermina Fandos dan Carlor Flavin. 2008. Customer Satisfaction A Key Faktor Of Customer Loyalty And Buying Intention Of a DPO Food Product. British Food Journal, 110(9), pp. 865-881.

Goh, Nan Jiang, Pei Leng Tee. 2016. The Impact of Brand trust, Self-image Congruence and Usage Satisfaction toward Smartphone Repurchase Intention. International Review of Management and Marketing. Vol.6, 2016.

Hanggara, V.\& Brahmana, R.M.K.R. 2005. Pengaruh Brand Personality Teh Javana Terhadap Purchase Intention Melalui Pendekatan Self-Image Congrunece. Student Journal. Vol.3, No.1.

Irawan, Handi. 2008. Membedah Strategi Kepuasan Pelanggan. Cetakan pertama PT Gramedia: Jakarta.

Kotler dan Grey Armstrong. 2004. Dasar-dasar Pemasaran 9/e. Jilid 1. Jakarta: PT. Indeks.

Kotler, P. 2005. Manajemen Pemasaran, Jilid 1, Edisi 13. Jakrata: Erlangga.

Kotler, Philip dan Kevin Lane Keller. 2008. Manajemen Pemasaran. Edisi ketigabelas jilid 1. Jakarta: Indeks.

Kotler, Philip dan Kevin Lane Keller. 2009. Manajemen Pemasaran Edisi Ketigabelas Jilid 1. Jakarta: Erlangga.

Lindquise, J., \& Sirgy ,M.J. 2009. Shopper, Buyer, And Customer Behavior (4th ed). Ohino Mason: Cengange Learning.

Nikbin, D., Ismail, I., Marimuthu, M., \& Younis Abu-Jarad, I. (2011). The Impact of firm reputation on customers'responses to service failure: the role of failure attributions. Business Strategy Series, 12(1), 19-29.

Nugroho, dkk. 2015. Pengaruh Atribut Produk Terhadap Kepuasan Pelanggan Dan Loyalitas Pelanggan (Survei pada Counter Perdana di Gresik). Jurnal Manajemen Bisnis, Vol.20, No.1, Maret 2015.

Sugiyono. 2010. Metode Penelitian Kuantitatif Kualitatif Dan RED Cetakan Ke 11. Bandung: Alfabeta.

Tjiptono. 2001. Manajemen Pemasaran Jasa. Edisi Kedua. Andy Offset, Yogyakarta.

Tammabua, Milcha Handayani. 2017. Analisis Pengaruh Self Image Congruity, Retail Servise Quality, Dan Customer Perceived Servive Quality Terhadap Customer Loyalty Yang Dimediasi Customer Satisfaction Urban Surf/Distro Di Jayapura. Jurnal Organisasi Dan Manajemen. Volume 13, Nomor 2, September 2017.

Widjiono, Japarianto. 2015. Analisa Pengaruh Self Image Congruity, Retail Service Quality Dan Customer Perceived Service Quality Terhadap Repurchase Intention Dengan Customer Satisfaction Sebagai Variabel Intervening Dib Roadway Barbershop Surabaya. Jurnal Manajemen Pemasaran, Vol.9, No.1, April 2015. 